\title{
Proposal of Dissemination and Broadcasting of Laboratory Data within Small Time Latencies
}

\author{
Ladislav Madarász ${ }^{1}$, Vladimír Gašpar ${ }^{1 *}$, Imre J. Rudas ${ }^{2}$, Rudolf Andoga ${ }^{3}$, Luboš \\ Gašpar $^{4}$
}

'Department of Cybernetics and Artificial Intelligence, FEEal TU Košice, Letná 9, 04200 Košice, Slovak Republic

${ }^{2}$ Faculty of John von Neumann, Óbuda University Budapest, Bécsi út. 96/b, 1034 Budapest, Hungary

${ }^{3}$ Department of Avionics, Faculty of Aeronautics, TU in Košice, Rampová 7, 04121 Košice, Slovak Republic

${ }^{4}$ Crypto group, UCL, Place du Levant 3, B-1348 Louvain-la-Neuve, Belgium

\section{BIOGRAPHICAL NOTES}

Dr. h. c. prof. Ing. Ladislav Madarász, PhD., was born in 1949 and is currently a professor at Department of Cybernetics and Artificial Intelligence, FEEal, TU Košice. In 1984 he received a title assoc. prof. and in year 1994 professor in field of Technical Cybernetics. In 2009 he received a title Dr. h. c. at Miskolc university and in 2010 he was awarded by Honorary professor at Óbuda University Budapest. He is a member of scientific committees at Faculty of Aeronautics, TU Košice and University of Selye János in Komárno. His most notable results are creation of concept of design, implementation and runtime of situational control in complex systems, design of novel structure for the situational control of complex systems, the application of situational control (electrical network, robototechnological complexes, medical engineering, turbojet engines, etc.) and usage of elements of artificial intelligence in situational control, diagnostics and design of complex systems.

Ing. Vladimír Gašpar, was born in 1988 and is currently a PhD student at Department of Cybernetics and Artificial Intelligence, FEEal, TU Košice. He finished master's degree in 2011 in field of Business Informatics. His research field is oriented on qualitative parameters and their evaluation of complex thermodynamic systems and design of respective software and research information systems in this field. He is a member of "euroCRIS: Current Research Information System - The European Organization for International Research Information", "Slovak PhD students association" and "Business informatics PhD student research group".

Dr. h. c. prof. Dr. Imre J. Rudas DSc., was born in 1949 and is currently a professor and rector of Óbuda University, Budapest. He graduated from Bánki Donát Polytechnic, Budapest in 1971, received master's degree in Mathematicsfrom the Eötvös Loránd University, Budapest, the PhD. in robotics from the Hungarian Academy of Science sin 1987, while the doctor of sciences degree in 2004. He received his first Dr. h. c. from the Technical University of Košice, and the second from „Polytechnica“ Universit of Timisoara. He server as the rector of Budapest Tech from 1, august 2003, since. He is member of IEEE, Senior Administrative Committee member of IEEE Industrial Electronics Society, member of Board of Governors of IEEE SMC Society and Chair of IEEE Hungary Section. He is vice-president of IFSA, he was the president of Hungarian Fuzzy Association for 10 years. In research, he presents areas of Computational Cybernetics, Robotics, Soft Computing, Computer aided process planning, Fuzzy Control and Fuzzy sets.

Ing. Rudolf Andoga, PhD., obtained his masters degree in 2003 in the field of arti- 
ficial intelligence and got PhD. degree in 2007 in the field of control and automation with a thesis entitled "Hybrid algorithms in situational control of complex systems". He presently works as a specialist assistant at the Department of Avionics at the Faculty of Aeronautics of Technical Univesity of Košice. His professional research is aimed at adaptive algorithms of complex systems, situational control of complex systems, aircraft cybernetic systems and applications of artificial intelligence in avionic systems. He is an author of many scientific publications and has also participated on solution of projects (agencies:VEGA, KEGA, APVV, 7FP) in the areas of complex systems control and avionics.

Ing. Luboš Gašpar, PhD., was born in 1986 and is currently a post-doc researcher at Université catholique de Louvain (UCL) in Louvain-la-Neuve Belgium, financed by the European commission project (FP7 TAMPRES). He finished his master's degree in 2009 in field of Electronics and Telecommunications at TU Košice and in 2012 he defended the PhD thesis at Université de Lyon, Saint-Etienne, France in Laboratoire Hubert Curien. His research interests are cryptography, hardware security, signal processing and multi-processor embedded systems.

\section{KEY WORDS}

Broadcast, unicast, dataflow, UDP protocol, data measurement, multimedia stream, synchronization, remote dashboard.

\section{ABSTRACT}

This paper presents the possibilities of broadcasting and dissemination of experimental data, obtained from direct real-time measurements of a physical objects - small turbojet engine MPM-20. The key factor of this data transfer is to minimize latency of the data transfer and computational overhead that may slow down or jam the control computer. This is why the usage of UDP protocol has been proposed. Since the utilization of the existing measuring aperture with both original hardware (HW) and software (SW) acquisition equipment is necessary, the proposed solution is not created using modifications of original HW and SW modules but the addition of newly created ones. Whereas the remote monitoring of the MPM-20 also requires audiovisual (A/V) contact, we also propose a module to transfer $\mathrm{A} N \mathrm{~V}$ as a stream from an array of
IP cameras that are capturing the area of the object MPM-20 in the real time.

\section{Introduction}

Lately the dissemination of information and digital content has become a standard way of interactive learning, cooperative research as well as other activities mostly present in other university activities connected with research propagation. In case of systems, where it is possible to remotely monitor or even control the respective system (e.g. complex thermodynamic systems) the requirements for quality on-time data is essential. In the laboratory of intelligent control systems of jet engines (LIRS LM) the requirement of real-time online data transfer with possible broadcast is also becoming necessary, mostly due to international cooperation, remote research presentation and educational purposes [1][3][4]. However, there are constraints that need to be accepted for the solution to be applicable in this particular scenario.

There are several elements that are considered crucial in data exchange in general. In computer systems, one of the most important element is the time latency. When using protocols of higher network layers, more and more data overhead is created because of more complex services that are required for these layers. However, the usage of standard protocols, even on the transport layer (UDP or TCP), may be of use in case the system can handle small time latency (e.g. 1-150 ms). Differences between the protocols create the possibility of latency minimization [8].

Data quality and the receive rate is also important but mostly in applications, where the outage of several samples may degrade the whole system observation. In case the sampling rate is relatively high (10-100 samples per second) the monitoring activities (particularly in complex thermodynamic systems) can handle minor data outages, for example through prediction models or other types of intelligent algorithms.

Dissemination and broadcasting of any content usually requires connectivity with high bandwidth. This is why it is important to minimize amount of transferred data. If large amount of data is being transferred (e.g. AN content in FullHD or uncompressed raw $A / V$ ) a separate transfer line is usually required. From the hardware point of view, the optical line is necessary because it sufficiently meets 
the requirements of such amount of data in the transfer channel. However it is important to discover bottlenecks in the whole dataflow process including source machine, data conversion and encapsulation, transfer medium and protocols, data processing and finally the target machine.

The last but not the least important factor is the processor, memory and hard drive load of both the source and target machines. Separate processes that are used for calculations and mathematical evaluations should have lower processor time priority because they tend to clog other processes. In some cases, the priority leveling may not be a sufficient solution. To ensure low load level, computations should be done within processes that are critical for enough processor time supply. However, such solutions require modification of existing processes, thus reprogramming of state-of-the art software which is complicated and usually not efficient enough.

In this paper we take all previous factors in consideration. Some authors also stated the possibility of lower layer data transfer within one physical machine [8] but this approach is not applicable in conditions of LIRS LM laboratory because it would require the modification of existing SW and HW platform. This modification could create instability in the measuring aperture and related SW modules. The scenario and reasoning of selected and created solution is described in the experimental section of this paper.

The experimental section of this paper is concentrated on the creation of real-time data transfer scenario with detailed description of the scenario parameters.

\section{Multimedia Transfer Possibilities in LIRS LM}

The knowledge gained from the experiments will be implemented in the final solution - the transfer of data between LIRS LM laboratory (engine testing facility) with newly created multimedia lecture room (MLR) as the primary goal. Both of these objects are located on grounds of the Faculty of Aeronautics, Technical university of Košice. In the second iteration, we suggest that any computer connected to the internet will be able to connect to a remote server application and watch the live data and AN stream of the MPM-20 and TJ-100 engines running processes with respective visualization of virtual dashboards [2][4][6]. The final con- nection scenario has following elements:

- Unicast - Send data from Control PC in LIRS LM to "lirs/m.fei.tuke.sk" server

- Broadcast - Send data from LIRS LM server to connected workstations (clients) in MLR

- Capture and visualize data received from "lirs/m. fei.tuke.sk" data and A/V broadcast

\subsection{Network outage test}

There are some constraints that have to be taken into account. First of them is the physical layer of the network, which is currently represented by copper, shielded twisted pair cable and covered by $100 \mathrm{Mbps}$ of link speed (see Fig. 1). The connection speed is limited due to switch that is used as a basic connection component for home networks and is not suitable for fast and reliable data transfer. Moreover, the switch is also used as a repeater in a 150 meter branch of the network (see Fig. 1). Such a length is limiting for signal quality, thus the connection outages are common and the link quality is fairly low in this particular case.

To prove the need of upgrading original network to optical, we have carried out 5 separate ICMP protocol request/response measurements (100 packets in every measurement) and gained knowledge about mean number of outages and mean latency of the connection. The request source is the local control computer in the LIRS LM laboratory which should be the data source in the final scenario. The target has been set to the dissemination and data handling server "lirsIm.fei.tuke.sk" located in the ÚVT building of the Technical university in Košice (cca. 5 km optical cable length - see. Fig. 1).

Results, gained from the respective test are presented in Tab. 1. As we may see from the values, the percentage of outages is high, thus the quality of the network connection is insufficient to transfer large amounts of data sensitive to quality (A/V).

\subsection{Final data and $\mathrm{A} / \mathrm{V}$ transfer scenario}

If the deployment of the optical connection is finished the scenario of the data transfer will be carried out as described in the previous part of this chapter ( 3 elements of the final scenario). To ensure that the reliability of the transfer is high enough we need to separate computational tasks from visualization tasks. This is why it is logical to use two physically separate server machines that each handle different types of processor time sen- 


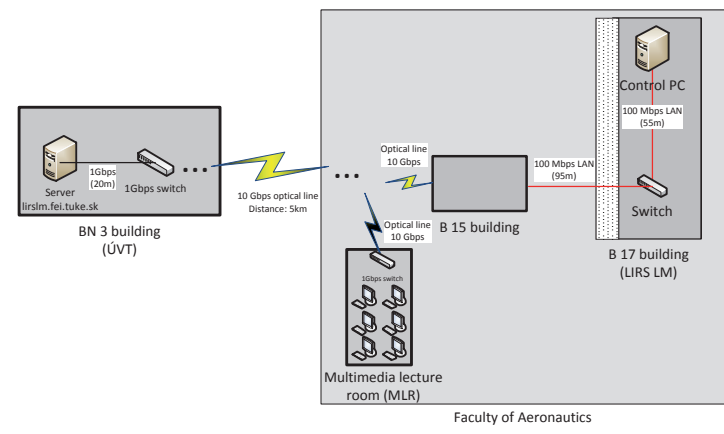

Fig. 1: Original scenario of the physical network layer for latency and outage test (red line-bottleneck).

Table 1: Values measured during the ICMP response/request test for non optical connection

\begin{tabular}{|l|l|l|l|l|}
\hline Measurement No & $\begin{array}{l}\text { Packet } \\
\text { loss } \\
\text { [\%] }\end{array}$ & $\begin{array}{l}\text { Latency } \\
\text { min } \\
\text { [ms] }\end{array}$ & $\begin{array}{l}\text { Latency } \\
\text { max } \\
\text { [ms] }\end{array}$ & $\begin{array}{l}\text { Latency } \\
\text { avg. } \\
\text { [ms] }\end{array}$ \\
\hline 1 & 16 & 0 & 31 & 1 \\
\hline 2 & 19 & 0 & 45 & 3 \\
\hline 3 & 17 & 0 & 20 & 2 \\
\hline 4 & 17 & 0 & 20 & 2 \\
\hline 5 & 19 & 0 & 7 & 2 \\
\hline
\end{tabular}

sitive tasks. As we have stated earlier, the "lirslm.fei. tuke.sk" will handle computational part and data colleting. This server is already hosting several client - server based application and is optimized for this particular type of tasks. The second server will handle AN content, its capturing, storage and streaming. Particularly storage and streaming is a task that requires high computer performance.

\subsection{Computational load minimization}

As it was stated in the introduction, one of the main problems is not to clog the control pc with too much overhead data for sending. Multimedia content is rather large and compression processes require lots of computational time. The best solution to overcome this issue is to load the network that will be extended for this purpose, instead of the control PC. We can achieve this load distribution using IP cameras instead, connected directly to the LAN network instead of web cameras that have to be connected to a computer. The burden of sending the data in time however stays on the control PC. A separate application for data sending would create excessive load of the control computer. This is why the sending of the data has to be implemented in the processor time sensitive applications as we have stated earlier in the introduction. To achieve this state, we may modify the scheme for data acquisition, which is a LabView scheme. LabView and Matlab Simulink are two processes that need the greatest amount of processor time during real-time measurements of the MPM20 engine.

Implementation of a UDP sender is simple and does not create excessive load, thus does not clog the control computer. The UDP sender implementation scheme in LabView is presented in Fig. 2.

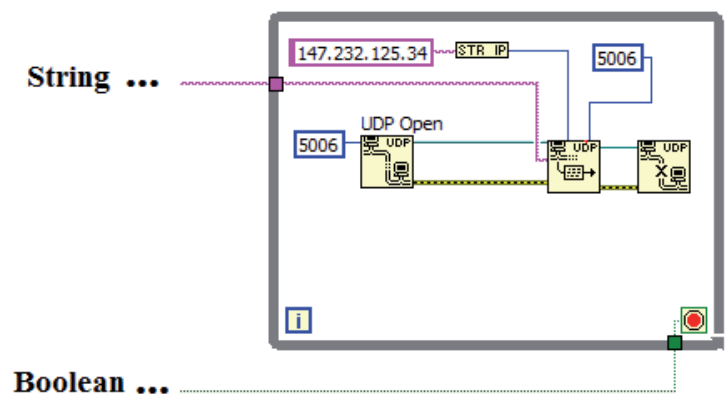

Fig. 2: UDP sender implemented in LabView.

Elementary data from measurements will be received on the server side by a separate receiving application and synchronized with AN content stream from the second server "analytics.fei.tuke. sk". Synchronization is done according to timestamp that need to be sent with each data or AN package from the sources. The receiving process will be done on a 5006 UDP port at the "lirsIm.fei. tuke.sk" machine. After the data and AN stream content is synchronized, the data along with the AN content will be presented on a server hosted application. This scenario describes a typical UNICAST communication frame.

\subsection{Dissemination and dataflow}

The dissemination of the data and $A / V$ is done by client connection to the mentioned server application, which will be accessible from the internet and secured using SSL standard and a certificate of the respective server. The whole dataflow architecture with the implementation of all described services in the presented project is depicted in Fig. 3. 


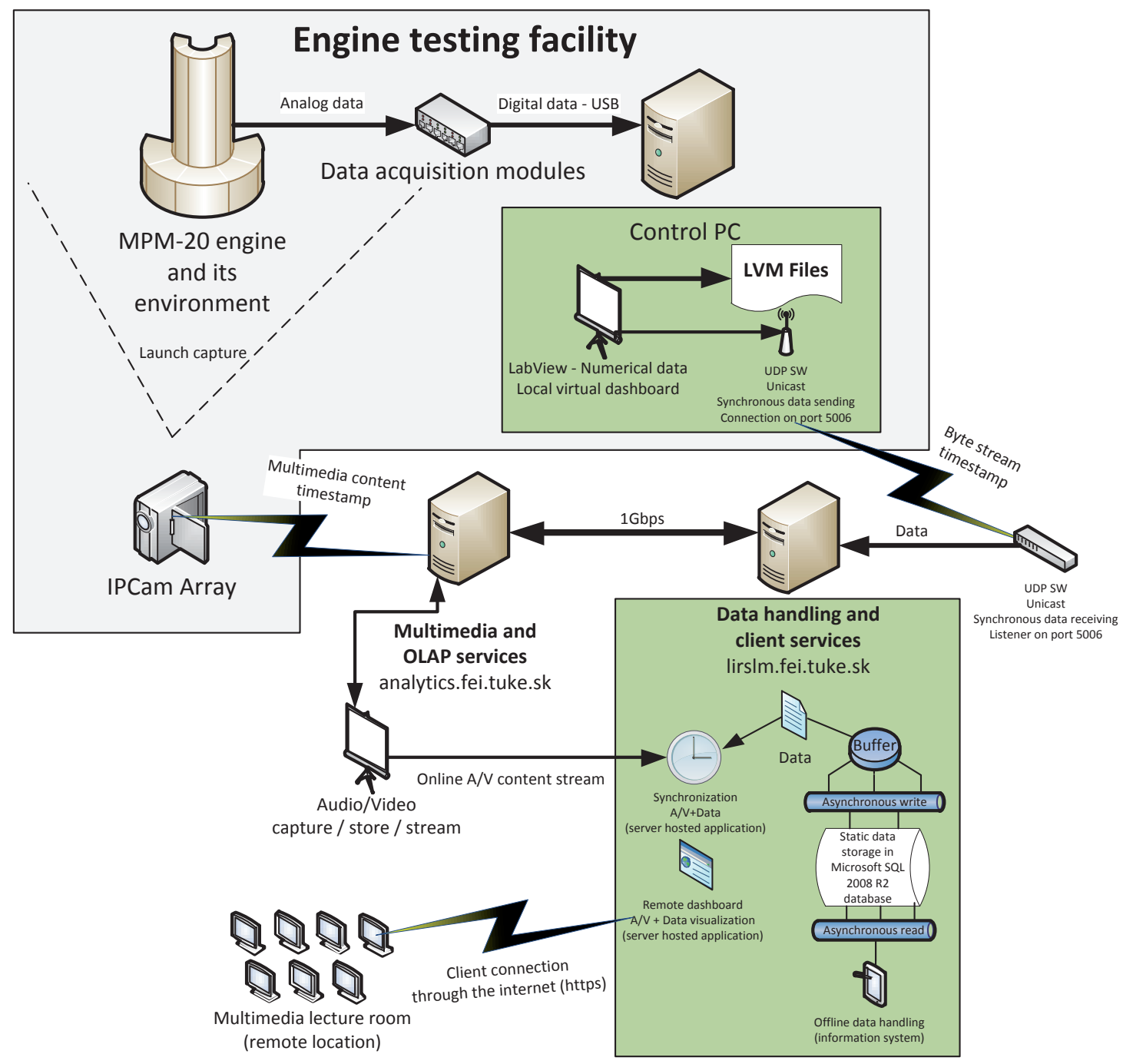

Fig. 3: Dataflow architecture of the LIRS LM laboratory

\section{Concept Simulation Results}

To test the proposed solution, we created an experimental setup:

- Separate UDP sender program, started on PC connected to a broadband internet connection (Fig. 4)

- Separate UDP receiver program, started on the "lirsIm.fei.tuke.sk" server machine (Fig. 5).

- We performed the same ICMP test as in the chapter 2.1 with sufficient results (Tab.2).

- Real experimental data file with 14144 values (13 variables $x 108,8$ seconds $\times 10$ samples/s)

- One data package per cca. 1KB of data (1024 byte buffer)

In this experiment we sent only data without the AN content and with good network infrastructure. Also to demonstrate the possibility of on-time data receiving in a remote internet location (ADSL broadband) outside the local TUNET network we selected a basic home PC, which we connected to the 5006 UDP port, opened on "lirslm.fei.tuke.sk" server. We carried out the data sending scenario for 5 times and the time in which the data was received was averaging around $1100 \mathrm{~ms}(1,1 \mathrm{~s})$ as it may be seen in Fig. 5

\section{Conclusions}

In this paper we proposed and constructed a 


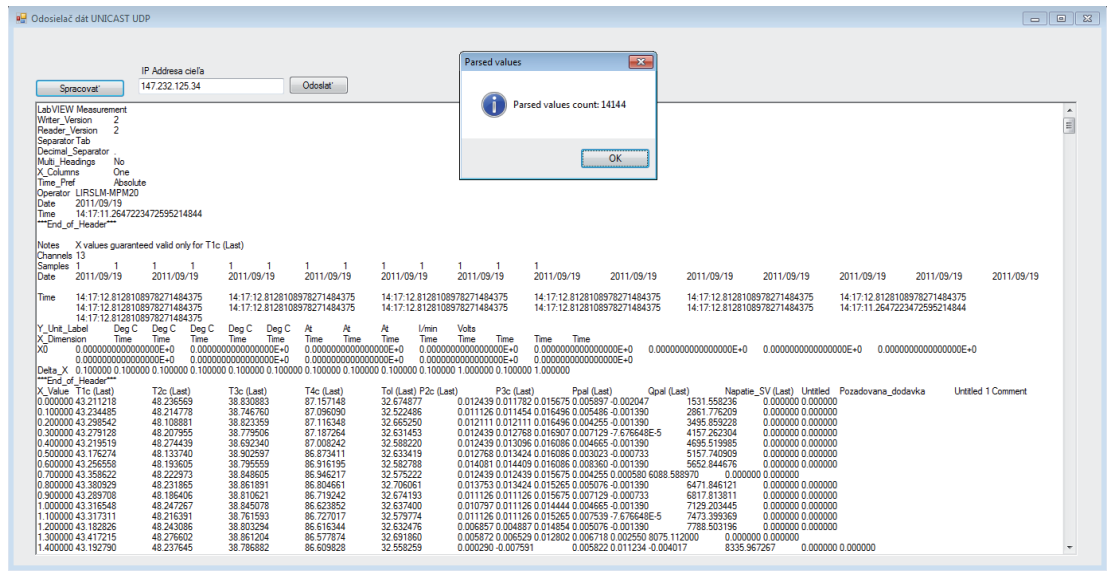

Fig. 5: UDP receiver application for laboratory data without AN.

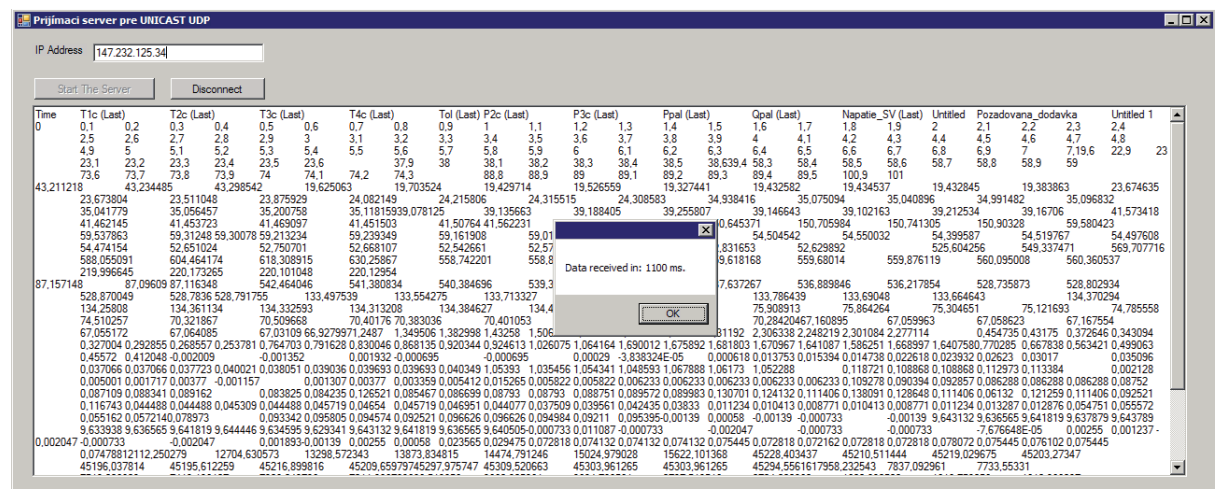

Fig. 4: UDP sender application for laboratory data without AN.

Table 1: ICMP test for broadband connection.

\begin{tabular}{|l|l|l|l|l|}
\hline Measurement No & $\begin{array}{l}\text { Packet } \\
\text { loss } \\
{[\%]}\end{array}$ & $\begin{array}{l}\text { Latency } \\
\text { min } \\
{[\mathbf{m s}]}\end{array}$ & $\begin{array}{l}\text { Latency } \\
\mathbf{m a x} \\
{[\mathbf{m s}]}\end{array}$ & $\begin{array}{l}\text { Latency } \\
\text { avg. } \\
\text { [ms] }\end{array}$ \\
\hline 1 & 1 & 17 & 34 & 18 \\
\hline 2 & 0 & 16 & 18 & 17 \\
\hline 3 & 2 & 17 & 65 & 18 \\
\hline 4 & 0 & 15 & 18 & 17 \\
\hline 5 & 0 & 16 & 18 & 17 \\
\hline
\end{tabular}

possible solution for fast and reliable data transfer without severe modifications to the existing software and hardware platform of the laboratory. However, we present the idea of building an optical line connection to the laboratory, which is currently being build and will soon be available for further experiments. This is why so far we have only created a simulation outside the local TUNET network, which should have lower latencies than the tested broadband internet connection. Moreover, we proposed a concept to join multimedia audiovisual content and data into a single server application using UDP unicast for data and AN streaming with time synchronization. We assume that completion of the proposed scenarios and implementation of the concept will be beneficial not only for the educational purpose but also to demonstrate measurements for a wider circle of researchers or public in the future. We expect to complete these works until the end of the 018TUKE-4/2012 "Progressive methods of education in the area of control and modeling of complex systems object oriented on aircraft turbo-compressor engines." KEGA project, since they are one of its final expected practical results.

\section{Acknowledge}

The work presented in this paper was supported by VEGA, Grant Agency of Ministry of Education and Academy of Science of Slovak Republic under Grant 
No. 1/0298/12 - "Digital control of complex systems with two degrees of freedom". The work presented in this paper was also supported by KEGA under Grant No. 018TUKE-4/2012 - "Progressive methods of education in the area of control and modeling of complex systems object oriented on aircraft turbocompressor engines."

\section{References}

[1] GAŠPAR, V., MADARÁSZ, L.: Information system implementation concept for qualitative parameters of a technical system. In: proceedings NOVUS SCIENTIA 2013. 10 april 2013. Faculty of Mechanical Engineering, TU, Košice. 5pp. ISBN 978-80-553-1381-8.

[2] LAZAR, T., MADARÁSZ, L. et al.: Inovatívne výstupy z transformovaného experimentálneho pracoviska s malým prúdovým motorom (Innovative outputs from the transformed experimental laboratory with a small turbojet engine) elfa, s.r.o., Košice. 2011. 348 pp. ISBN 978-80-8086-170-4.

[3] LAZAR, T., MADARÁSZ, L., ANDOGA R., GAŠPAR, V.: Obzor a potenciál efektívnosti laboratória LIRS LM (Outline and potential of LIRS LM efficiency) - 2013 In: proceedings Aeronautika 2013, LF TU, Košice, Herlany, Slovak Republic. 4pp.

[4] LAZAR, T., MADARÁSZ, L., GAŠPAR, V.: Procesná analýza odhadu efektívnosti identifikácie MPM s inteligentným riadením. (Estimation process analysis of identification effectiveness of small turbojet engine with inteligent control) elfa, s.r.o. Košice, 2013. 160pp. ISBN 978-80-8086-200-8.

[5] MADARÁSZ, L.: Inteligentné technológie a ich aplikácie v zložitých systémoch (Intelligent Technologies and their applications in complex systems), University Press elfa, 2004. 348 pp. ISBN 80-89066-75-5.

[6] MADARÁSZ, L., et al.: KEGA č. 001-TUKE - 4/2010 „Využitie inteligentných metód riadenia a modelovania leteckých motorov vo výukovom procese" - (2010-2011)

[7] MADARÁSZ, L., et al.: KEGA č. 018 TUKE - 4/2012 „Progresívne metódy výučby riadenia a modelovania zložitých systémov objektovo orientované na letecké turbokompresorové motory" - (2012-2014)

[8] ZHOU, W., LI, Q., CAESAR, M., Godfrey, P.B.: ASAP: A low-latency transport layer. ACM CoNext 2011, 6-9.12.2013, Tokyo, Japan. ISBN 978-1-4503-1041-3

[9] STANDARD - RFC 768 (1980), User datagram protocol, J. Postel ISI, Uniter States of America.

[10] STANDARD - RFC 675 (1974), Internet transmission control protocol, V. Cerf, United States of America.

[11] Network topology maps of Technical University of Košice (ÚVT) 